\title{
Indígenas e ensino superior: as experiências universitárias dos estudantes Kainganng na UFPRS
}

\section{Valesca Daiana Both Ames* Marilis Lemos de Almeida ${ }^{* *}$}

\section{Resumo}

Desde 2008, a Universidade Federal do Rio Grande do Sul (UFRGS), como parte de sua política de ações afirmativas, destina anualmente dez vagas para estudantes provenientes de comunidades indígenas em seus cursos de graduação. A presença desses sujeitos, historicamente ausentes do espaço universitário, representa um momento enriquecedor, tanto para os estudantes quanto para a própria instituição, mas também traz consigo muitos desafios. Este artigo analisa as experiências universitárias de alguns estudantes Kaingang na UFRGS - etnia que representa 85\% dos alunos indígenas ingressantes na instituição. Mais especificamente, examina como eles acompanharam os conteúdos de seus cursos de graduação e como se relacionaram com colegas não indígenas e com professores. Os resultados mostram as dificuldades no uso, reprodução e apropriação dos conhecimentos acadêmicos enfrentadas pelos indígenas na tarefa de se tornarem estudantes universitários, bem como o tipo e a qualidade das relações estabelecidas com colegas e professores. Concluímos que o processo de aprendizagem do ofício de estudante é mais árduo e lento para os estudantes indígenas, tendo em vista as baixas expectativas de ingressar no ensino superior, a sua formação escolar precária, a falta de diálogo intercultural na universidade e as situações preconceituosas e discriminatórias vivenciadas no interior da UFRGS.

Palavras-chave: estudantes indígenas, ensino superior, ações afirmativas, aprendizagem.

* Universidade Federal do Paraná, Curitiba, PR, Brasil.

** Universidade Federal de Pelotas, Pelotas, RS, Brasil. 


\section{Indigenous people and higher education: the university experiences of Kaingang students at UFRGS}

\section{Abstract}

Since 2008, the Federal University of Rio Grande do Sul (UFRGS) has annually allocated ten places for students from indigenous communities in its undergraduate courses, as part of its affirmative action policy. The presence of these subjects, historically absent from the university space, represents an enriching moment for both students and the institution itself, but it also brought with it many challenges. The article analyzes the university experiences of some Kaingang students at UFRGS - an ethnic group that represents $85 \%$ of indigenous students entering the institution. More specifically, it examines how they followed the content of their undergraduate courses and how they related to non-indigenous colleagues and teachers. The results show the difficulties in the use, reproduction and appropriation of the academic knowledge faced by the indigenous in the task of becoming university students, as well as the type and quality of relationships established with peers and teachers. We conclude that the learning process of the student's craft is more arduous and slower for indigenous students, considering: the low expectations of entering higher education; the precarious educational background of these subjects; the lack of intercultural dialogue at the university and the prejudiced and discriminatory situations experienced within the UFRGS.

Keywords: indigenous students, higher education, affirmative actions, learning.

\section{Introdução'}

presença de estudantes indígenas nas universidades brasileiras é um
fenômeno recente, incentivado pela implementação de diversas
políticas e ações no ensino superior público e privado a partir da década de 2000. Entre essas medidas, destacam-se as políticas de ações afirmativas, as quais visam incrementar a presença de sujeitos pertencentes a grupos considerados minorias sociais ou categorias socialmente desfavorecidas - como negros, indígenas, pessoas com deficiência e de baixa renda - em

${ }^{1} \mathrm{O}$ artigo apresenta parte dos resultados da tese de doutorado da primeira autora. A pesquisa foi realizada com o auxílio financeiro da Coordenação de Aperfeiçoamento de Pessoal de Nível Superior (CAPES). 
cursos de graduação, por meio de distintos mecanismos de inclusão, como a reserva de vagas, a criação de vagas e o sistema de bonificação.

As políticas de ações afirmativas para os povos indígenas no ensino superior público foram inicialmente implementadas por meio da promulgação de leis estaduais e por iniciativa das próprias universidades. O primeiro estado a adotar tal medida foi o Paraná, que reserva, desde 2001, vagas para candidatos indígenas em suas universidades estaduais; já a primeira instituição de ensino superior federal a estabelecer vagas para indígenas foi a Universidade de Brasília, a partir de 2004. Posteriormente, no início da década de 2010, mais precisamente em 2012, a adoção dessas medidas tornou-se Lei Federal - no $12.711 / 2012$. A citada Lei previu a reserva de $50 \%$ das vagas de instituições de ensino superior federal para estudantes oriundos do ensino médio público, das quais uma parte seria destinada para candidatos autodeclarados pretos, pardos e indígenas, em proporção no mínimo igual à sua presença nos estados federativos onde se situam as instituições (Brasil, 2012).

No que se refere ao ensino superior privado, tem-se a criação, em 2005, do "Programa Universidade para Todos" (Prouni), o qual estabeleceu a concessão de bolsas para estudantes autodeclarados indígenas, de baixa renda e que tenham frequentado escolas públicas, sendo a proporção de bolsas novamente correspondente à presença de indígenas nos estados de localização das universidades.

Se podemos entender o ingresso de indígenas nas instituições de ensino superior brasileiras como um resultado das ações e políticas levadas a cabo a partir da década de 2000, também é importante analisarmos por que estes povos passaram a buscar formação em nível superior. Com efeito, podemos identificar dois movimentos distintos, mas historicamente conectados, que contribuíram para fomentar esta procura. O primeiro se relaciona ao crescimento das práticas de escolarização em terras indígenas nos ensinos fundamental e médio, a partir da década de 1990, que resultou na busca por parte desses sujeitos pela continuidade dos seus estudos no ensino superior - principalmente voltados para a formação e qualificação 
de professores para atuarem nas escolas indígenas. O segundo se associa à nova relação estabelecida com o Estado após a promulgação da Constituição Federal de 1988. Efetivamente, a nova carta constitucional assegurou direitos específicos aos povos indígenas ${ }^{2}$ e reconheceu a sua cidadania plena, fazendo crescer entre esses sujeitos o desejo e a necessidade de adquirir conhecimentos não indígenas que os pudessem capacitar para dialogar com a sociedade mais ampla e atuar em projetos e ações de interesse de suas comunidades (Lima; Barroso, 2013; Paladino, 2013).

Esse contexto possibilitou que se registrasse um aumento significativo no número de indígenas em universidades públicas e privadas a partir da década de 2000. Conforme Paladino (2012), em 2003 havia aproximadamente 1.300 indígenas no ensino superior, dos quais cerca de sessenta a setenta por cento em instituições privadas. Em 2011, estima-se que sete mil indígenas cursavam o ensino superior, em universidades públicas e privadas, passando a somar dez mil em 2013.

$\mathrm{O}$ ingresso de estudantes indígenas nas universidades brasileiras constituiu uma novidade que colocou a questão da diversidade e da experiência multicultural e pluriétnica em seu interior, trazendo consigo muitos aprendizados, desafios e dificuldades. Segundo pesquisas acerca da presença indígena nas universidades, as principais dificuldades enfrentadas pelos estudantes podem ser divididas em três diferentes tipos: a) econômicas, referentes ao acesso à moradia, transporte, alimentação, compra de materiais didáticos, entre outros; b) pedagógicas, relativas à aprendizagem de novos conteúdos de conhecimentos, em um contexto no qual, normalmente, não há "concessão de qualquer tipo de flexibilização de conteúdos, metodologias, material didático, calendário etc." (Paula, 2013, p. 804); e c) interpessoais, referentes às relações com pessoas não indígenas, como os colegas de turma, docentes e funcionários técnico-administrativos, as quais podem dar origem a experiências de preconceito e discriminação (Paladino, 2012).

${ }^{2}$ A Constituição de 1988 garantiu direitos aos povos indígenas sobre as terras tradicionalmente ocupadas, sobre sua organização social, costumes, línguas, crenças e tradições (Brasil, 1988). 
Tendo em vista, então, a novidade representada pela inserção de indígenas nas universidades brasileiras e a complexidade desse fenômeno, neste artigo concentramos nossa atenção sobre um caso particular, a Universidade Federal do Rio Grande do Sul (UFRGS). ${ }^{3}$ Esta universidade, desde 2008, destina anualmente dez vagas suplementares para o ingresso de estudantes indígenas em seus cursos de graduação, como parte de sua política de ações afirmativas.

Particularmente, temos o intuito de analisar as experiências universitárias dos estudantes indígenas Kaingang na UFRGS - etnia que, segundo Doebber (2017), representa 85\% dos alunos indígenas ingressantes na instituição -, dando ênfase a duas dimensões dessas experiências. A primeira, denominada "intelectual", faz referência ao conceito de "afiliação intelectual", cunhado pelo sociólogo francês Alain Coulon (2008). Com esse conceito, o autor busca entender como os estudantes aprendem os códigos e regras que balizam a vida universitária no que diz respeito ao uso, construção, reprodução e exibição do conhecimento - saber quando e como falar, apropriar-se do vocabulário acadêmico, ler e escrever de modo eficaz, desenvolver a concentração e organizar os horários de estudos (Coulon, 2008). A segunda, chamada "relacional", se refere à qualidade das relações estabelecidas pelos estudantes com seus colegas de turma e com professores. Essa dimensão é especialmente relevante porque o processo de tornar-se estudante universitário implica a criação de vínculos com os demais alunos e a realização de atividades conjuntas que permitam a eles "reconhecer que enfrentam os mesmos problemas, utilizam as mesmas expressões e partilham o mesmo mundo" (Coulon, 2008, p. 107). Ademais, a qualidade dessas relações influencia o desempenho dos alunos "no que diz respeito

\footnotetext{
${ }^{3}$ A UFRGS esteve entre as universidades brasileiras a adotar uma política de ações afirmativas para indígenas antes da aprovação da Lei de Cotas, contemplando atualmente (2020) 13 anos de implementação da mesma. Além disso, foi uma das primeiras universidades federais do Rio Grande do Sul a criar uma política de ingresso e permanência para indígenas assim como a UFRGS, a Universidade Federal de Santa Maria (UFSM) também instituiu uma política para acesso de indígenas em 2008.
} 
a um melhor aproveitamento acadêmico e a uma melhor adaptação à universidade" (Soares; Mourão; Mota, 2016, p. 17).

Para apreendermos essas duas dimensões das experiências universitárias dos estudantes Kaingang da UFRGS, utilizamos técnicas qualitativas de coleta e análise dos dados. Particularmente, realizamos 14 entrevistas semiestruturadas - de agosto a dezembro de 2016 - com estudantes matriculados em diferentes cursos de graduação da instituição, ${ }^{4}$ assim como observações de cunho etnográfico por um período de aproximadamente um ano, de abril a dezembro de 2016, no "Grupo de Acolhimento aos Estudantes Indígenas" (GAIn) ${ }^{5}$ da UFRGS e nos seminários "O que é ser índio?", desenvolvidos por esse grupo. O material empírico foi analisado por meio da análise de conteúdo temática (Bardin, 2011), com o auxílio do software Nvivo.

\section{Acesso, permanência e características dos estudantes indígenas da UFRGS}

A criação de um Programa de Ações Afirmativas na UFRGS foi aprovada em junho de 2007 (Decisão no 134/2007), após dois anos de intensas atividades voltadas ao estudo e debate em torno desta política. No que se refere especificamente aos indígenas, como dito anteriormente, ficou estabelecida a criação anual de dez vagas suplementares àquelas ofertadas pela instituição, em distintos cursos de graduação, escolhidos em diálogo

${ }^{4}$ Os entrevistados distribuem-se entre os cursos de Odontologia (3), Direito (2), Fisioterapia (2), Serviço Social (2), Medicina (1), Enfermagem (1), Psicologia (1), Pedagogia (1) e História (1).

${ }^{5}$ O GAIn foi criado em 2014, por iniciativa dos estudantes indígenas do curso de Serviço Social da UFRGS. O grupo tem como um de seus principais objetivos auxiliar, do ponto de vista pedagógico, os estudantes indígenas no acompanhamento dos seus cursos de graduação. Nesse sentido, constitui-se como um coletivo formado pelos próprios estudantes indígenas, bem como por seus monitores e orientadores. 
com representantes das comunidades indígenas Kaingang, Guarani e Charrua do Rio Grande do Sul. ${ }^{6}$

Com a finalidade de acompanhar os processos seletivos dos candidatos indígenas, bem como a permanência dos ingressantes na instituição, a UFRGS constituiu, em 2008, a Comissão de Acesso e Permanência do Estudante Indígena (CAPEIn), vinculada à Secretaria de Assuntos Estudantis (SAE). Essa Comissão - junto com a Comissão de Acompanhamento dos Alunos do Programa de Ações Afirmativas, responsável pelos demais alunos cotistas - foi extinta em 2012, após uma revisão da política adotada pela universidade (Resolução 268/2012), sendo substituída pela Coordenadoria de Acompanhamento do Programa de Ações Afirmativas (CAF), ligada à Pró-Reitoria de Coordenação Acadêmica (UFRGS, 2012).

Para concorrer a uma das vagas disponibilizadas, os candidatos indígenas participam de um Processo Seletivo Específico (PSE), composto por duas provas - uma de Língua Portuguesa, com 25 questões de múltipla escolha, e uma de Redação - construídas com o intuito de abranger temas importantes para os povos indígenas. Como critério de identificação étnica dos candidatos, a referida universidade solicita a entrega de uma autodeclaração étnico-racial e de uma declaração da própria comunidade indígena - assinada por, pelo menos, uma liderança e outros dois membros da mesma, e homologada pela Fundação Nacional do Índio (FUNAI) (UFRGS, 2017b).

Além de garantir o acesso específico aos indígenas, a UFRGS também disponibiliza um conjunto de benefícios socioeconômicos, apoios pedagógicos e ações voltadas para auxiliar os ingressantes. Os benefícios socioeconômicos oferecidos são: ingresso preferencial na moradia estudantil, acesso com isenção de custos ao restaurante universitário, auxílio financeiro para compra de materiais didáticos, para transporte, creche e participação em eventos.

${ }^{6}$ Além das vagas para indígenas, o referido Programa previu a reserva de 30\% das vagas do vestibular para alunos que completaram pelo menos a metade do ensino fundamental e a totalidade do ensino médio em escolas públicas, sendo $50 \%$ dessas destinadas a autodeclarados negros. Esse Programa foi posteriormente modificado para adequar-se à Lei de Cotas. As vagas suplementares destinadas aos indígenas, por seu turno, não sofreram alterações. 
O apoio pedagógico é desenvolvido por meio do "Programa de Monitoria Indígena", em que são designados um professor orientador e um estudante monitor responsáveis pelo acompanhamento do estudante indígena em seu primeiro semestre na universidade ${ }^{7}$. Há ainda a realização de atividades de acolhimento aos novos alunos, assim como o desenvolvimento de eventos e cursos de capacitação voltados à reflexão a respeito da presença indígena na universidade. Cabe, por fim, destacar que os alunos indígenas possuem direito a uma bolsa de estudos, denominada Bolsa Permanência, concedida pelo Ministério da Educação, no valor de 900 reais mensais, a qual não exige contrapartida em atividades na instituição.

Desde a implementação da política afirmativa, os cursos da área da Saúde e da Educação estão entre os majoritariamente selecionados pelos representantes das comunidades indígenas, seguindo uma "tendência nacional na escolha por cursos que possuem relação direta com as necessidades das comunidades" (Bergamaschi; Doebber; Brito, 2016). Notadamente, considerando o intervalo temporal de 2008 a 2017, os cursos escolhidos com maior frequência foram: Medicina e Enfermagem, em todos os processos seletivos; Odontologia, Direito e Pedagogia, selecionados oito vezes; História e Serviço Social, escolhidos sete vezes; Nutrição, Saúde Coletiva, Fisioterapia e Psicologia, selecionados quatro vezes; e Agronomia, Educação Física e Ciências Biológicas, escolhidos três vezes.

Os estudantes indígenas classificados ${ }^{8}$ nos processos seletivos da UFRGS pertencem principalmente à etnia Kaingang - eles representam 84,4\%. ${ }^{9} \mathrm{No}$ que se refere à localidade de origem, são provenientes, em sua maioria, do Rio Grande do Sul (RS) - estado de origem de 98\% deles. As terras indígenas mais representadas são: Guarita, com 17,7\%; Nonoai, com 14,6\%; Lomba do Pinheiro, com 10,4\%; e Votouro, com 8,3\% do total (UFRGS, 2017a).

${ }^{7}$ O Programa de Monitoria Indígena pode ser solicitado para os semestres subsequentes mediante justificativa e com a condição de que o estudante não tenha completado sessenta por cento dos créditos de seu curso.

${ }^{8}$ Nas 100 vagas disponibilizadas durante os dez anos de vigência da política (2008-2017) foram classificados 96 candidatos (UFRGS, 2017a).

${ }^{9}$ Seguidos dos Guarani, com 12,5\%, e dos Fulni-ô, Juruna e Quechua, com 1\% cada. 
Com exceção da Lomba do Pinheiro, as demais localidades encontram-se na mesorregião noroeste do RS.

No que diz respeito ao gênero, as mulheres são prevalentemente representadas entre os classificados em relação aos homens, constituindo, em média, 58,3\% do total. Quanto à idade, notamos forte presença de estudantes jovens: 44,7\% estão na faixa etária dos 20 aos 25 anos, enquanto 29,8\% têm até 19 anos - ou seja, 74,5\% dos classificados têm no máximo 25 anos (UFRGS, 2017a).

De acordo com Doebber (2017), dos 95 estudantes indígenas que ingressaram na UFRGS desde 2008, 57 permaneciam matriculados (60\%) e seis diplomaram-se (6,3\%) nos cursos de Enfermagem (2012), Direito (2013), Pedagogia (2014 e 2015), Medicina (2015) e Serviço Social (2016). ${ }^{10}$ Os demais 32 estudantes (33,7\%) encontravam-se nas seguintes situações: três em trancamento de matrícula, quatro desistiram das vagas, 23 foram desligados por abandono e dois estavam em processo de desligamento. Ainda segundo a mesma autora, dos estudantes considerados evadidos da UFRGS, pelo menos dez ingressaram em outras instituições públicas de ensino superior.

A elevada taxa de evasão dos acadêmicos indígenas da UFRGS, segundo Bergamaschi, Doebber e Brito (2016, p. 177), pode ser considerada como um "processo de fabricação das desistências", decorrente da rigidez dos processos educacionais da instituição e da "pouca ou nenhuma abertura para outras formas de produzir e expressar conhecimento". Ora, para lançarmos luz sobre essa questão e analisarmos como ocorre a inserção universitária dos indígenas, com as dificuldades e experiências inerentes a esse processo, consideramos importante pontuar previamente alguns aspectos relativos às suas formações escolares, às expectativas nutridas em relação ao ensino superior e as consequentes atitudes com vista ao ingresso na instituição.

${ }^{10}$ Houve também um estudante indígena diplomado no curso de Medicina e um no curso de Odontologia, em 2018. 


\section{Formação escolar, preparação para os processos seletivos e a escolha dos cursos}

Os estudantes indígenas entrevistados realizaram o ensino básico exclusivamente em escolas públicas, tendo seus percursos caracterizados, majoritariamente, por uma transição entre escolas indígenas e não indígenas, após a finalização das primeiras quatro séries do ensino fundamental ou durante a passagem para o ensino médio - dependendo da oferta dos estabelecimentos escolares indígenas localizados em suas comunidades.

O ingresso no ensino superior, de modo geral, não integrava o projeto de vida dos entrevistados. Ao contrário, os relatos mostram que a decisão de tentar entrar na universidade ocorreu de forma quase imprevista, como algo até então inesperado. Em alguns casos, acessar esse nível de formação não constituía um desejo, pois "terminar o ensino médio já estava bom"11 (lara, Pedagogia, 20 anos); outros, embora tivessem essa vontade, não percebiam condições objetivas para realizá-la, tendo em conta, por um lado, os altos custos envolvidos com a formação acadêmica na rede de ensino privada e, por outro, a grande competitividade dos processos seletivos das instituições públicas. Nesses aspectos, a condição dos estudantes indígenas se aproxima daquela dos alunos das camadas populares, pois, como apontado por Piotto e Alves (2016), em muitos casos, também para esses o prolongamento dos estudos após o ensino médio não fazia parte de suas perspectivas de vida, mas surgiu como uma possibilidade a partir de acontecimentos e/ou situações pontuais e imprevistas que acabaram influenciando as suas trajetórias.

No caso dos estudantes indígenas, a implementação das políticas de ações afirmativas foi fundamental para que o acesso à universidade se constituísse como uma possibilidade concreta. Eles formaram, em regra, a primeira geração de suas comunidades e famílias a ingressar no ensino superior. Foi igualmente importante para os entrevistados o compartilhamento

11 Optamos por preservar a identidade de nossos entrevistados, adotando nomes fictícios para nos referirmos aos mesmos. 
das experiências universitárias recentes de amigos ou familiares indígenas, que forneceram informações a respeito do processo seletivo para indígenas da UFRGS - instituição até então desconhecida para alguns deles. Essa questão vai ao encontro do que afirma Oliven (2007, p. 47), a respeito da influência positiva das experiências universitárias de estudantes de origem social mais baixa e de estudantes negros e indígenas sobre seu grupo familiar e de amizade, em comparação ao que ocorre entre aqueles provenientes das classes sociais média e alta:

numa sociedade como a brasileira, que por anos apresentou o índice de concentração de renda maior do mundo, pobres e negros são raros na comunidade acadêmica. Os alunos provenientes de famílias da elite pouco têm a acrescentar a seus familiares e amigos em termos de capital cultural. Por outro lado, alunos, cuja origem social é mais baixa, e alunos negros, que costumam ser a primeira geração a frequentar a universidade, tendem a contribuir muito mais para aumentar os conhecimentos e as expectativas educacionais de seus familiares, principalmente de irmãos mais novos.

A maioria dos estudantes entrevistados afirmou não ter realizado estudos preparatórios para o processo seletivo. Aqueles que se prepararam, o fizeram após a inscrição e exclusivamente de maneira individual - ou seja, sem terem frequentado grupos de estudos ou cursinhos pré-vestibulares. Podemos compreender essa escassa preparação dos indígenas para as provas seletivas se levarmos em conta que a possibilidade de ingressar no ensino superior se apresentou em suas vidas de forma súbita e não planejada, conforme salientamos anteriormente.

De acordo com os entrevistados, a escolha do curso de graduação foi marcada por dificuldades, tanto pela falta de informações pessoais a respeito dos mesmos, quanto pela restrição das opções ofertadas pela instituição. ${ }^{12}$ Este último fato os levou, em alguns casos, a escolher cursos distintos daqueles inicialmente desejados. Essas duas dificuldades fizeram

${ }^{12}$ Como vimos, a UFRGS oferece dez diferentes cursos para o ingresso de indígenas por ano, escolhidos em diálogo com representantes das comunidades indígenas. 
com que alguns estudantes se orientassem, prioritariamente, para as áreas de conhecimento que consideravam mais interessantes:

eu fui ver e queria Educação Física. Eu gostava de esportes e tal. Eu queria Educação Física, mas a UFRGS não tinha disponibilizado Educação Física, pois ela disponibiliza os dez cursos, e não tinha. Eu vi lá: "Fisioterapia", local "Campus Olímpico", "Escola de Educação Física". Daí já pensei: "vou fazer isso aqui então!". E também me aproxima da área do esporte, a Fisioterapia tem uma área específica, esportiva. Resolvi fazer, mais porque não tinha... se tivesse Educação Física, eu faria, certo. Mas, vim parar na Fisioterapia (Leonardo, Fisioterapia, 23 anos).

Embora os estudantes indígenas tenham afirmado não possuir informações específicas sobre os cursos que escolheram nos processos seletivos, disseram, majoritariamente, que seus interesses se relacionaram às demandas por profissionais qualificados para trabalhar no interior das comunidades indígenas, na esperança de fornecer futuramente um retorno a elas. Particularmente, eles destacaram a importância da formação de profissionais que possam atuar levando em conta as especificidades culturais e políticas de seus povos.

Os diferentes aspectos até aqui destacados a respeito das perspectivas e atitudes dos entrevistados diante da possibilidade de ingressar no ensino superior - baixa expectativa de entrar na universidade, escassas informações sobre os processos seletivos e sobre os cursos a serem frequentados, pouco ou nenhum tempo dedicado a estudos preparatórios - podem se transformar em barreiras para a inserção destes na universidade. Com efeito, de acordo com Merton (1970), a socialização antecipatória com vista ao ingresso em um determinado grupo é um dos aspectos que podem facilitar a posterior adaptação, na medida em que, possivelmente, os sujeitos ajustarão previamente seus comportamentos e adotarão normas e valores característicos do grupo por eles visado. De outra parte, passando para a análise de nosso caso, podemos supor que aqueles estudantes indígenas que não perspectivavam ingressar no ensino superior e que, por isso, não orientaram seus comportamentos ou adotaram valores típicos da 
universidade, teriam mais dificuldades para adquirir o status de estudante universitário e lidar com as normas, códigos e regras a ele inerentes. Levando isso em consideração, na próxima seção analisaremos como os estudantes indígenas da UFRGS lidaram com as demandas características da vida universitária.

\section{A árdua tarefa de se tornar estudante universitário}

Segundo Coulon (2008), tornar-se um estudante universitário implica aprender um novo ofício, com suas próprias rotinas, práticas e códigos. Particularmente, significa incorporar novas referências intelectuais, aprender a utilizar de forma adequada o vocabulário acadêmico, saber se organizar para realizar os estudos, enfim, adaptar-se a um novo contexto. Esse processo de aprendizagem não é fácil e se realizaria em três fases, denominadas pelo autor: a) o tempo do estranhamento, durante o qual os estudantes "perdem suas referências anteriores" e "percebem um mundo que não é mais familiar"; b) o tempo da aprendizagem, em que os alunos estão começando a lidar com as novas demandas da vida universitária, porém ainda se sentem "inseguros" e "ansiosos"; e, por fim, c) o tempo da afiliação, no qual os estudantes dominam os "códigos que balizam a vida intelectual" e tornam-se definitivamente membros da cultura universitária (Coulon, 2018, p. 40-41).

Entre as principais rupturas experienciadas pelos recém-ingressantes no ensino superior está a diferença entre as exigências do ensino médio e aquelas da universidade "em termos de vocabulário, de conceitualização, de hábitos de leitura e de escrita, de pensamento, enfim, de um conjunto de operações intelectuais que caracterizam o trabalho acadêmico" (Coulon, 2008, p. 68). Essas novas exigências dariam lugar a um conjunto de dificuldades para os estudantes. Na pesquisa realizada com os acadêmicos indígenas, eles mencionaram três tipos principais de dificuldades, relativos à compreensão e uso da linguagem acadêmica, à compreensão dos conteúdos ensinados 
e ao domínio das habilidades práticas necessárias para a realização do trabalho intelectual.

As dificuldades com a linguagem acadêmica se referem aos problemas de compreensão e domínio das palavras e expressões utilizadas tanto pelos professores em sala de aula quanto presentes nos materiais de estudos. É um léxico até então parcialmente desconhecido para alguns dos estudantes indígenas, o que trouxe consequências para o acompanhamento das explicações realizadas pelos docentes e para o entendimento dos textos trabalhados nas disciplinas. A não apropriação dessa linguagem comprometeu ainda a expressão oral e escrita dos referidos alunos:

por exemplo, uma palavra complicada, assim, que até hoje eu fico pensando é "recíproca". Eu nunca tinha ouvido falar nessa palavra. Eu fui em uma prova e pensava: "Meu Deus, o que eu vou colocar?". Então, são coisas simples, que para nós acabam se tornando... (Renata, Psicologia, 24 anos).

O escasso domínio da linguagem acadêmica expressa pelos estudantes indígenas se relacionou, em primeiro lugar, à própria compreensão da língua portuguesa, tendo em vista que alguns deles possuem como primeira língua o Kaingang e também nela foram inicialmente alfabetizados. Sobre esse aspecto, assim afirmou Denize, diplomada no curso de Enfermagem: "eu tive contato com a aula de português mesmo só na quarta ou quinta série", "quem fala mais em português, conhece mais palavras do que nós que só falamos em Kaingang" (Doebber, 2017, p. 174).

Ademais, podemos relacionar essa dificuldade dos estudantes indígenas às diferenças entre o uso da linguagem em seus contextos familiares e comunitários e na universidade. Com efeito, como mostra Bourdieu (2007), o manejo e a compreensão da linguagem escolar (proximidade com a norma culta, domínio do vocabulário e da sintaxe) são influenciados pelo meio social e linguístico de origem. Nesse sentido, alunos provenientes das famílias de classes média e alta, herdariam uma determinada relação com a língua culta - um dos componentes do capital cultural, reproduzido na instituição escolar - que facilitaria o êxito em seus estudos. Em contrapartida, 
estudantes oriundos de classes populares, não tendo sido socializados previamente na linguagem demandada pela instituição escolar, realizariam um esforço maior para decodificá-la. Ora, é plausível pensarmos que as referidas dificuldades dos estudantes indígenas resultam do pouco domínio da língua culta, valorizada e exigida na universidade.

A segunda dificuldade mencionada pelos entrevistados é relativa à compreensão dos conteúdos ensinados, agravada pelos problemas de entendimento dos materiais didáticos indicados pelos professores. Segundo alguns estudantes indígenas, os conteúdos expostos em sala de aula e presentes na bibliografia de apoio introduziam informações e autores até então desconhecidos e distantes de suas realidades indígenas, nos quais disseram não se reconhecer. Sobre esses aspectos, afirmaram Sara (27 anos) e Adriana (24 anos), do curso de Serviço Social, respectivamente:

era muita teoria, de autores que a gente nunca ouviu falar. É muito pensamento que a gente tem que estudar: Marx, Weber. Eu não entendia bem. Agora, se eu leio um texto deles, consigo compreender. Mas antes não, era muito difícil. Eu lia, lia, lia e não sabia o que estava lendo, não estava entendendo.

No meu curso teve vários conhecimentos e pensamentos que eles passaram, mas eu não consegui encaixar os indígenas nesse conhecimento. A questão que a gente estuda muito em Marx, que estuda a sociedade, o homem, e para mim o indígena... Eu não me encaixava nisso.

As dificuldades de entendimento das explicações realizadas pelos docentes em sala de aula foram trazidas especialmente pelos estudantes dos cursos de maior prestígio social - como Medicina, Odontologia e Direito. Conforme esses alunos, grande parte de seus professores não realizavam explicações suficientemente claras e aprofundadas, de modo que pudessem acompanhar os conteúdos com maior facilidade. O motivo, segundo eles, se relacionaria ao fato de que os professores pressupunham que a totalidade dos estudantes compartilhasse a mesma base de conhecimentos do ensino médio. Podemos recorrer novamente às contribuições de Bourdieu (2007) para interpretar essa questão. De acordo com o autor, os professores, ao 
ensinarem, partiriam da hipótese de que existiria, entre eles e os seus alunos, referências culturais e conteúdos compartilhados, além de uma linguagem comum, fato que só se verificaria caso o sistema escolar (ou, no nosso caso, universitário) estivesse lidando com os seus próprios herdeiros - ou seja, com alunos já socializados na cultura escolar, porque próxima àquela transmitida em suas próprias famílias.

Por fim, a terceira dificuldade relatada pelos entrevistados diz respeito ao domínio das habilidades práticas necessárias para a realização do trabalho intelectual: "saber concentrar-se", "fazer um plano", "saber ler mantendo a atenção para não adormecer" (Coulon, 2008, p. 115). Ou, nas palavras dos acadêmicos indígenas, saber "como estudar": quais partes dos textos são mais importantes e devem receber uma atenção especial? Onde posso encontrar os materiais necessários (livros, artigos) para realizar os meus estudos?

E no começo eu não sabia como estudar, porque lá [na escola onde realizei o ensino médio] eu estudava um dia antes para as provas, ia fazer e era aquela coisa, fácil. E aqui não, o nível é elevado. E eu não sabia como estudar, não sabia o que estudar, eu pegava o cronograma e ficava [pensando]: "o que eu faço?" (Fernanda, Odontologia, 19 anos).

Saber como estudar também envolve, como já dissemos, a capacidade para conseguir se concentrar. Esse é outro ponto problemático apontado pelos estudantes indígenas, que não conseguem ficar "um bom tempo estudando": "é muito difícil eu conseguir me concentrar duas ou três horas seguidas. No máximo é uma hora e para, volta mais uma hora e para trinta minutos" (Fernanda, Odontologia, 19 anos).

As dificuldades com o acompanhamento das disciplinas são identificadas por muitos estudantes indígenas como o principal desafio que encontraram para permanecer na UFRGS. Podemos compreender este período inicial como um tempo de aprendizagem, no qual, como afirma Coulon (2008, p. 40), os estudantes "não têm mais passado, mas também ainda não têm futuro. Ele [o estudante] está no espaço entre dois momentos e não tem 
mais referências". Esse é o período em que existe a maior possibilidade de abandono da instituição. Por exemplo, lara (20 anos), estudante de Pedagogia, havia desistido de seu curso de graduação, porque se sentiu desestimulada "com as coisas que não conseguia fazer", tendo retornado para a sua comunidade indígena, onde permaneceu durante cinco meses, até decidir retomar os seus estudos:

lara: Eu desisti, eu fui embora, no semestre passado. Era agosto, eu acho, a formatura da Adriana. ${ }^{13}$ Eu vi a foto dela no facebook e fiquei pensando. Eu já tinha desistido. Então, liguei para Mariana [técnica em assuntos educacionais do curso de Pedagogia] e disse: "eu quero voltar!". Já tinha passado o prazo para eu me matricular e ela fez de tudo para eu poder voltar. E eu consegui. Voltar... Acho que foi por eu ver as fotos no facebook. Eu fiquei bem emocionada com a formatura dela e pensei: "será que eu não vou conseguir fazer isso?". Parece que isso me motivou muito.

Valesca: E quanto tempo tu tinhas ficado na comunidade?

lara: Fiquei uns cinco meses fora. Eu não iria mais voltar, mas eu voltei.

Valesca: E por que tu acabastes voltando para a tua família, a tua comunidade?

lara: É que alguns dias eu achava, quando eu não conseguia fazer alguma coisa que os professores mandavam eu fazer, tipo um trabalho... Eles não tinham muito... Não tinha muito... Eu ficava desanimada com as coisas que eu não conseguia fazer, quando eu não conseguia fazer um trabalho direito. Foi isso que me desanimou e eu desisti, peguei as coisas e fui. Foi por isso.

Embora esse tempo de aprendizagem do qual nos fala Coulon (2008) seja comum a um conjunto de estudantes que passam do ensino médio para a universidade, podemos supor que ele seja mais árduo e lento para os alunos indígenas, tendo em vista a baixa expectativa nutrida em relação ao ingresso no ensino superior - conforme salientamos na seção anterior -, a formação escolar precária desses sujeitos e a falta de diálogo intercultural na universidade.

Efetivamente, em relação ao segundo aspecto destacado, os entrevistados associaram as dificuldades enfrentadas no acompanhamento das disciplinas

${ }^{13}$ Indígena formada em agosto de 2016, no curso de Serviço Social da UFRGS. 
à baixa qualidade da formação escolar básica, que não os teria preparado para as exigências da universidade, como afirmou a estudante Renata (20 anos), do curso de Psicologia:

eu sei que um professor não está ali esperando uma guria que, como eu, me formei e dois anos depois fui procurar a universidade. Até hoje, eu não sei a tabuada de cor, se tu me perguntares. Eu nunca fiz um relatório para entregar valendo nota. Tem coisas simples que eu poderia ter construído lá na oitava série até o terceiro ano. Isso deveria ser construído, porque hoje na universidade, as coisas não seriam assim. [...] A gente aprenderia o que os outros que estão aqui aprendem. Mas não, a gente não tem isso. E lá [nas comunidades indígenas] o ensino é muito precário.

Dessa forma, a carência de conhecimentos que poderiam ter sido adquiridos no ensino básico colocou em desvantagem os alunos indígenas ao iniciarem seus estudos universitários. Embora a monitoria e a orientação tenham se constituído como apoios didáticos importantes para esses alunos, não parecem ter sido suficientes para sanar as suas lacunas formativas. Amaral e Baibich-Faria (2012, p. 827), na pesquisa que realizaram com estudantes indígenas das universidades estaduais do Paraná, da mesma maneira afirmam que

a fragilidade no domínio de conteúdos escolares é um dos motivos por eles apresentados para ruptura do pertencimento acadêmico, revelados pelos índices de evasão, pelo desânimo em continuar estudando e, consequentemente, pelo desejo de permanência nas aldeias, principalmente nos períodos de férias ou feriados prolongados.

Quanto ao terceiro aspecto acima mencionado, estamos nos referindo particularmente à escassa presença de temas relativos à cultura indígena nas disciplinas frequentadas pelos estudantes indígenas - fato que, como vimos, teria dificultado o acompanhamento dos cursos por parte de tais estudantes, por não se reconhecerem, enquanto indígenas, naquilo que estava sendo ensinado. Com efeito, pesquisa realizada por Ames (2019) sobre o papel dos docentes na formação dos alunos indígenas da UFRGS 
mostrou que poucos professores modificaram os conteúdos tendo em vista a presença de um indígena em sala de aula. Dentre os motivos indicados (como limitações de ordem pessoal e estrutural), destacou-se a falta de orientação institucional para lidar com as demandas formativas de tais estudantes - em alguns casos, os professores sequer foram informados que teriam um indígena entre os seus discentes. Esse fato nos interroga, portanto, a respeito do papel da própria universidade na formação dos alunos indígenas, a qual, nas palavras de Bergamaschi, Doebber e Brito (2016, p. 177), ainda "não consegue estabelecer um diálogo mais consistente com estes povos", visto que se mostra pouco aberta ao reconhecimento de diferentes valores e visões de mundo.

As dificuldades enfrentadas pelos entrevistados e a percepção de diferenças em relação aos demais colegas ${ }^{14}$ deram origem a questionamentos a respeito de seu pertencimento ao contexto acadêmico, como se eles não tivessem "pleno direito de estar ali no espaço da universidade" (Heringer, 2014 , p. 28). Para ilustrar essa questão, destacamos a fala do estudante Leonardo (23 anos), do curso de Fisioterapia:

até agora estou aqui, mas pensei muitas vezes em desistir. Na sala de aula, o professor perguntava alguma coisa, e eu não tinha ideia do que era, e o meu colega do lado sabia, e eu pensava: "O que estou fazendo aqui? Isso aqui não é para mim!". Chegava em casa, chorava, "trabalho para fazer, não sei por onde começar. O que é isso? Que palavra é essa?". Eu passei por uma barra, até o semestre passado, o ano passado, eu pensava em desistir, porque é uma coisa muito diferente, nossa!

O sentimento de "estrangeirismo" em relação à universidade, como um espaço diferente e distante de suas próprias realidades, também foi evidenciado por Amaral (2010, p. 398) em pesquisa que realizou com acadêmicos Kaingang e Guarani das universidades estaduais paranaenses: "alguns entrevistados respondem associando esse sentimento às influências do seu processo de escolarização básica, vivenciado de formas diferenciadas

${ }^{14}$ Os acadêmicos indígenas possuem, via de regra, apenas estudantes não indígenas como seus colegas. 
por cada um dos estudantes indígenas, articulado à sua formação étnico identitária".

Para lidar com as dificuldades enfrentadas no acompanhamento das disciplinas, os estudantes entrevistados afirmaram "estudar primeiro as coisas do ensino médio e depois o que o professor estava falando" (Érica, Medicina, 21 anos), ou seja, eles buscaram compensar as suas desvantagens estudando uma maior quantidade de conteúdos. Essa tarefa foi realizada por meio do acompanhamento de videoaulas e da leitura de materiais complementares àqueles indicados pelos professores. Além disso, eles trouxeram, sempre que possível, a temática indígena ou os conhecimentos produzidos no seio de suas comunidades nos trabalhos acadêmicos ou nas discussões promovidas em sala de aula - em geral, isso ocorreu em uma ou duas disciplinas ao longo de seus cursos de graduação.

\section{Relações e aprendizagem na UFRGS}

No processo de inserção na vida universitária, a qualidade das relações que os novos estudantes estabelecerão com seus colegas de curso, com seus professores e com estudantes mais antigos será decisiva, podendo operar como elemento facilitador ou dificultador da aprendizagem. Segundo os depoimentos dos estudantes entrevistados, as relações com os seus colegas foram bastante diferenciadas: se, por um lado, estabeleceram vínculos de amizade ou coleguismo; por outro, vivenciaram situações de conflito e marginalização.

No que se refere às relações de amizade ou coleguismo, Joana (23 anos), por exemplo, estudante do curso de Enfermagem, disse que foi bem recebida por seus colegas, descritos como bastante acolhedores. Ela comentou que existiu uma dinâmica de cooperação entre eles para a superação de eventuais dificuldades: "se tem uma pessoa com dificuldade, a gente pega, vai lá e procura dar um jeito de ajudar".

Por outro lado, como dito, os estudantes indígenas relataram dificuldades para estabelecer ou manter relações positivas com os seus 
colegas. As razões apontadas podem ser divididas em três tipos, relativos à instabilidade de seus contatos, pois alguns trocaram de turma ao longo de seus percursos acadêmicos, por conta das reprovações que obtiveram em algumas disciplinas; às suas próprias características pessoais, tendo em vista que muitos consideraram-se tímidos e introspectivos, aspecto que teria dificultado o estabelecimento de contatos e eventuais relações com as pessoas próximas, em uma espécie de "falta de associações por escolha" (Mannheim, 1970, p. 156-157); e ao comportamento indiferente e por vezes hostil de alguns de seus colegas.

Assim, podemos dizer que as relações dos estudantes indígenas com seus colegas foram caracterizadas por uma ambivalência, ou seja, por processos contemporâneos e contraditórios de inclusão e exclusão (Simmel, 1986). Isso significa que tais relações não podem ser identificadas nem como unicamente positivas, nem como unicamente negativas. Essa ambiguidade, no entanto, não pode ser interpretada como algo positivo, pois sinaliza que grande parte desses alunos sofreu com situações sutis ou manifestas de exclusão.

Efetivamente, muitos estudantes afirmaram se sentir isolados, ignorados, como se estivessem "invisíveis" em sala de aula:

muitas vezes eu tinha que dizer: "olha, pessoal, eu estou sem grupo". Parecia que eu estava invisível na sala. Como diz o Pedro [monitor] para mim: "olha, Renata, tu sentas muito na frente". Mas, o pessoal ali viu que eu estava sem grupo ou que talvez as minhas dificuldades fossem maiores do que as deles. Muitas vezes eles não... [...] Eu fico totalmente isolada. Mas, no começo também [se refere ao primeiro semestre], eu ficava lá na frente, sozinha (Renata, Psicologia, 24 anos).

Segundo Agnoli (2004) e Cipollini (2002), na base de comportamentos negativos, como os direcionados aos acadêmicos indígenas está um conjunto de representações sociais, sentimentos e disposições de natureza preconceituosa. De acordo com os estudantes entrevistados, os comportamentos de distância social ou hostilidade de alguns de seus colegas estariam relacionados a questionamentos sobre a legitimidade de sua 
presença na UFRGS, tendo em vista dois aspectos: o fato de terem ingressado na instituição por meio de ações afirmativas e de não corresponderem ao estereótipo formado sobre o que é ser indígena.

Com relação ao primeiro aspecto, destacamos a fala de Juliana (22 anos), estudante de Odontologia, que disse ter passado por uma situação constrangedora quando um de seus colegas comentou que ela "não deveria estar ali", pois estava "pegando vagas de outras pessoas". A mesma situação foi vivenciada por outros estudantes indígenas dos cursos de Odontologia, Medicina e Enfermagem. Com base nisso, é plausível supormos que, para alguns dos colegas dos indígenas, pertencer legitimamente à universidade significa ingressar por meio das formas de acesso universais. Podemos interpretar esse fenômeno recorrendo ao modelo de relações entre estabelecidos e outsiders, proposto por Elias e Scotson (2000) ao analisarem as relações entre os antigos e novos grupos de moradores da comunidade inglesa Winston Parva. De acordo com os autores, a presença de novos residentes nessa comunidade, os quais não compartilhavam o universo de valores, representações e estilos de vida dos antigos moradores, gerou um sentimento de ameaça à identidade, prestígio e posições sociais do antigo grupo, colocando em prática mecanismos de defesa e distância social. No nosso caso, os estabelecidos - como mencionamos, alguns estudantes não cotistas da UFRGS - parecem igualmente perceber a própria posição como proeminente e legítima, enquanto, por outro lado, julgam a presença dos estudantes indígenas, ingressantes por meio de uma política de ações afirmativas, como uma ameaça para o acesso à universidade de outras pessoas consideradas mais merecedoras - representado pela frase: "você está pegando vagas de outras pessoas" - e uma invasão simbólica - como percebemos por meio da afirmação: "você não deveria estar aqui". A reserva de vagas para um público específico por meio de critérios como o pertencimento racial e/ou étnico parece ser considerada por esses estudantes como profundamente injusta, dando a entender que os alunos cotistas estariam "roubando" posições de outros candidatos que teriam mais direito a ocupá-las. 
Como dito, alguns entrevistados também foram questionados, sob o argumento da baixa distintividade cultural, a respeito de seus pertencimentos étnicos. Isso ocorreu com alunos dos cursos de Odontologia e Direito. Esses questionamentos significam negar o que os indígenas afirmam ser com base em estereótipos formados sobre eles e compartilhados por alguns estudantes da UFRGS. A negação da identidade indígena pelo estereótipo do que é ser indígena e pela consequente afirmação de assimilação ao modo de vida urbano expressa uma luta simbólica sobre o direito de estar na universidade e pode operar como um mecanismo poderoso de deslegitimação das reivindicações étnicas. No caso dos acadêmicos indígenas, esse estereótipo ${ }^{15}$ correspondeu a uma imagem de indivíduos que habitavam em florestas, que faziam uso de arco e flecha e que adotavam um tipo específico de vestimenta. Conforme Mazzara (2000, p. 139, tradução nossa), "na presença de um estereótipo" os sujeitos tendem inicialmente "a verificar se a pessoa em questão corresponde às expectativas dele derivadas, agindo de maneira correspondente".

Quando eu entrei [na UFRGS] tive problemas em relação a colegas dizendo que eu já não era indígena por usar um tipo de vestimenta, pelo que eu comia, pelo que eu fazia, pelo que eu usava, já descaracterizando que eu não era mais membro de um povo, de uma coletividade, como se eles soubessem o que é ser indígena (Mário, Direito, 22 anos).

Também coexistiu um processo de construção e projeção de estigmas sobre os cotistas - dentre eles, os indígenas - os quais foram inferiorizados em relação às suas capacidades intelectuais por parte de alguns de seus colegas de turma. Essa situação foi relatada pelos estudantes dos cursos de Fisioterapia e Direito. Os processos de estigmatização dos outsiders, bem documentado por Elias e Scotson (2000), consiste na atribuição das características negativas de uma minoria anômica à totalidade dos membros

15 Segundo Mazzara (2000), podemos definir o estereótipo como um conjunto compartilhado, integrado e estável de representações simplificadoras sobre as características de determinados grupos sociais, que possuem a capacidade de se consolidar no tempo, resistindo a eventos que as contradigam. 
de um determinado grupo. Esse é um dos meios utilizados pelos grupos para, por um lado, afirmar a própria superioridade e, por outro, construir a inferioridade dos outros. Destacamos novamente a fala de Mário:

as pessoas hoje nos veem como os caras que entraram pela porta dos fundos, nos veem diferentes. E isso é um problema porque se reflete na sala de aula. Eu lembro que ninguém queria me convidar para fazer trabalho em grupo porque "ah, entrou com uma provinha lá, muito capenga, ele não sabe nada, vamos deixar assim, deixa ele lá, ele faz o trabalho dele e a gente faz o nosso".

Como sugere o relato acima, as relações que os estudantes indígenas mantiveram com seus colegas foram influenciadas pelas imagens construídas sobre eles. Essa relação, por sua vez, terá um papel importante no acompanhamento dos cursos pelos citados alunos, tanto por questões objetivas, que se expressam na possibilidade de acessar os materiais de leituras, de se inserir em grupos de estudos, de conseguir informações sobre as disciplinas, quanto subjetivas, expressa pela maior ou menor motivação em continuar estudando. Como afirmam Oliven e Bello (2017, p. 355-357),

muitos dos problemas de baixo desempenho de estudantes pertencentes a minorias estigmatizadas são de origem não apenas acadêmica [...] Oportunidades e informações importantes dependem, em grande parte, de nosso círculo de relacionamento. Redes de amizade social e racialmente homogêneas favorecem os privilegiados, nesse caso, estudantes brancos, em detrimento daqueles cujas famílias tiveram menores oportunidades de mobilidade social, em geral, negros.

De fato, a falta de vínculos colaborativos com os colegas dificultou a realização de trabalhos em grupos e o acesso a informações importantes relativas às disciplinas pelos acadêmicos indígenas, como podemos perceber por meio do seguinte depoimento:

o Mário falou um pouco dessa questão de quando faz trabalho em grupo e tu ficas sozinho. Quando o professor dava um trabalho "grupo de cinco!", eu ficava tremendo, com o coração acelerado, [pensando] "vou ficar sozinha de novo!". É uma coisa que me marca até hoje. [...] E isso dá um desânimo enorme na gente. Assim, eu não tinha estímulo para estudar. Eu ficava triste 
em saber que eu estava sendo ignorada em uma sala onde tinha trinta e poucos alunos. Eu ficava isolada. Na hora de sair, todo mundo nos seus grupos e eu me levantava devagar e saía também. la direto para o Centro [de Porto Alegre], porque, o que eu faria lá sozinha? Ninguém falava comigo (Débora, Fisioterapia, 26 anos, relato no Salão da UFRGS, em setembro de 2016).

Essas questões se apresentaram especialmente entre os estudantes indígenas que frequentavam cursos de alto prestígio social e com seleções muito competitivas. Esses cursos são compostos predominantemente por estudantes brancos, de classe média e alta e oriundos de escolas privadas e, por esses motivos, "tendem a apresentar uma atmosfera social excludente em que um estudante de outra cor, origem social e trajetória escolar passa a ser visto como uma presença estranha" (Oliven; Bello, 2017, p. 357).

Por outro lado, os estudantes indígenas que estabeleceram relações de amizade, colaboração e/ou apoio com os seus colegas, afirmaram que o auxílio recebido foi fundamental para o desenvolvimento de seus estudos - tanto em aspectos subjetivos quanto práticos -, como podemos notar por meio do seguinte relato:

tinha alguns colegas que entendiam que eu era um indígena e as dificuldades que eu tinha. E muitos me abraçaram: "poxa, ele precisa de um apoio, vamos dar um apoio para ele". [...] Eu fui fazendo amizades e eles me apoiaram em questões materiais, de estudo, me indicando bibliografia, dizendo como estudar. Então, foram me apoiando e entendendo os problemas que eu tinha (Mário, Direito, 20 anos).

A fala de Mário aponta, portanto, para a importância das relações positivas estabelecidas com os colegas, que o auxiliaram naquilo que constitui um dos aspectos mais difíceis do processo de tornar-se estudante universitário, que é "descobrir as rotinas, as evidências, as regras, os novos códigos da universidade" (Coulon, 2017, p. 1243), uma vez que nem tudo é passado explicitamente ou solicitado diretamente pelo professor e que mesmo o ato de estudar exige um aprendizado.

No percurso formativo dos estudantes indígenas, como já mencionamos, a relação com os professores é um aspecto particularmente importante. 
Os entrevistados, de maneira geral, disseram que suas relações foram "boas", "normais", descritas a partir da díade "professor-aluno". O que eles parecem indicar é que os professores desempenharam as funções que são socialmente esperadas. Essas funções são definidas por meio de um conjunto de regras de conduta exigidas pelos indivíduos que ocupam determinadas posições sociais - denominados papéis sociais (Cesareo, 1993). No caso dos professores, esse comportamento consistiu, de maneira geral, em ensinar e avaliar os alunos.

[A relação] é normal, "aluno-professor", mas nem meus colegas não são de ir lá conversar com os professores. Basicamente o professor chega, dá a aula e sai. Ou o professor chega, tem alguns que fazem piadinhas para interagir com a turma e fazem a gente dar risada, dá a aula dele, pergunta se alguém tem dúvida, e ele esclarece, marca prova, aplica prova e só (Fernanda, Odontologia, 19 anos).

No desempenho de suas funções, segundo os relatos dos estudantes indígenas, os professores se relacionaram, de maneira geral, com uma imagem genérica e pré-construída do que seriam as características dos seus alunos. Assim, não existiram espaços para a manifestação ou para a percepção de diferenças, sejam elas sociais, educacionais ou culturais. Nesse sentido, os indígenas constituíram "apenas mais um aluno" em sala de aula:

eles não têm aquela proximidade com o aluno, entender que ele tem uma dificuldade, que ele é de um povo diferente - um exemplo, que é o meu. Eles não entendem essas diferenças culturais. [...] Então, eles não têm uma relação mais próxima com os alunos. Isso se torna muito mais complicado na medida em que tem indígenas, tem negros, tem baixa renda, que têm seus problemas (como qualquer outra pessoa tem seus problemas), mas que afetam muito mais nós, indígenas, que temos um problema mais grave em relação a conteúdos, estudos, adaptação, entre outros diversos contextos dentro da universidade. Eles sequer param para entender ou ouvir o problema que a gente tem, para relatar as dificuldades que nós temos. Então, eles não dão muita importância para isso. Para eles, eu sou só mais um aluno, e tu és só mais uma aluna, como qualquer outro aqui dentro. As exceções existem, alguns acabam ouvindo e entendendo: "não, te entendo, vamos buscar algo". Mas, realmente, são raríssimas as ocasiões em que isso acontece (Mário, Direito, 20 anos). 
Por outro lado, como mencionado pelo estudante Mário, alguns professores desempenharam suas atividades levando em conta as dificuldades e diferenças dos seus alunos. Essa distinta postura foi relatada especialmente por duas estudantes indígenas entrevistadas do curso de Serviço Social. Segundo elas, os professores de seus cursos deram "mais atenção para quem era indígena", por meio de um acompanhamento mais próximo, que permitiu identificar suas dificuldades específicas e elaborar estratégias para enfrentá-las, como a realização de trabalhos de reforço e a indicação de monitorias específicas da própria disciplina. Podemos interpretar essa questão se considerarmos que os papéis sociais, embora constituam deveres e direitos socialmente estabelecidos, também comportam certa margem de liberdade aos atores que os desenvolvem. Nesse sentido, os professores, embora tenham o dever de ensinar, podem escolher o que ensinar e de que maneira, personalizando as suas ações de acordo com as suas características subjetivas (Cesareo, 1993).

Menos frequentes, porém muito graves, foram os depoimentos dos estudantes indígenas a respeito de situações de preconceito envolvendo seus professores. Essa situação foi apontada por duas alunas, dos cursos de História e Medicina. Segundo a estudante de Medicina, em sala de aula, um de seus professores se referiu aos povos indígenas de maneira pejorativa, pois disse que eles possuem uma "mordida mais forte, porque vivem comendo farofa com pedra". Na ocasião, a referida estudante se "levantou e saiu da sala". No entanto, teve dificuldades para acompanhar a disciplina, porque precisou estudar sozinha os conteúdos que foram trabalhados em sala de aula. Nesse caso, o tipo de interação estabelecida entre professor e aluno fortaleceu a sensação de não pertencimento ao espaço acadêmico, agravando as dificuldades inerentes ao processo de tornar-se estudante universitário. 


\section{Considerações finais}

Ingressar na universidade e aprender a seguir as suas rotinas, códigos e regras não é tarefa fácil e implica aprender o ofício de estudante, ou seja, adquirir o status de estudante universitário. Esse aprendizado, segundo Coulon (2008), se realizaria em três fases - denominadas o tempo do estranhamento, o tempo da aprendizagem e o tempo da afiliação - e seria influenciado por diversos fatores, dentre eles, a qualidade da formação escolar básica e as relações que os novos alunos estabelecerão com os demais atores universitários. Tendo isso em conta, no presente artigo analisamos a inserção universitária dos estudantes Kaingang na UFRGS, tomando como eixo central de interesse o modo como eles acompanharam os conteúdos de seus cursos de graduação e como se relacionaram com colegas e professores.

Assim, mostramos que, embora o tempo de aprendizagem das regras de uso, reprodução e apropriação dos conhecimentos acadêmicos seja difícil para os diversos alunos que passam do ensino médio para a universidade, ele é mais árduo e lento para os estudantes indígenas, tendo em vista especialmente três fatores. O primeiro se refere à baixa expectativa de ingressar no ensino superior -, pois este não integrava o projeto de vida dos entrevistados. Por conta disso, os estudantes indígenas, em geral, não se prepararam para as provas seletivas e tiveram dificuldades para escolher os cursos que seriam frequentados. O segundo diz respeito à formação escolar precária dos indígenas, que não os teria preparado para as exigências da universidade. Por fim, o terceiro fator se refere à falta de diálogo intercultural na universidade, que se expressa particularmente pela escassa inclusão de temas indígenas nas disciplinas dos cursos frequentados pelos referidos alunos.

Além disso, indicamos que a qualidade das relações estabelecidas pelos estudantes indígenas com seus colegas e professores foi um aspecto ora facilitador, ora dificultador da aprendizagem: efetivamente, aqueles alunos que desenvolveram relações de amizade, colaboração e/ou apoio lidaram 
de maneira mais positiva com as tarefas dos cursos por eles frequentados, pois, por exemplo, tinham mais facilidade para ingressar em grupos de trabalho e contavam com mais informações a respeito das disciplinas; por outro lado, os alunos que sofreram com manifestações preconceituosas e discriminatórias relataram, por exemplo, se sentir desestimulados a seguir estudando.

Por fim, evidenciamos neste artigo que os comportamentos preconceituosos e discriminatórios em relação aos indígenas parecem estar relacionados às imagens depreciativas compartilhadas por alguns de seus colegas e professores. Tais representações negativas colocaram em questão tanto a legitimidade da presença dos alunos cotistas na universidade, dentre eles os indígenas, quanto o pertencimento étnico desses últimos, com base em estereótipos do que é ser indígena. Esses argumentos expressaram uma luta simbólica sobre o direito de estar na universidade e operaram como um mecanismo de deslegitimação das reivindicações sociais e étnicas.

Valesca Daiana Both Ames é Doutora em Sociologia pela Universidade Federal do Rio Grande do Sul. Pós-doutoranda em Sociologia na Universidade Federal do Paraná.

$\triangle$ valesca.ames@gmail.com

Marilis Lemos de Almeida é Doutora em Política Científica e Tecnológica pela Universidade Estadual de Campinas. Professora da Faculdade de Direito e do Programa de Pós-Graduação em Sociologia da Universidade Federal de Pelotas.

$\triangle$ marilis_almeida@yahoo.com.br 


\section{Referências}

1. AGNOLI, Maria Stella. Lo straniero in immagine: rappresentazione degli immigrati e pregiudizio etnico tra gli studenti del Lazio. Milão: Franco Angeli, 2004.

2. AMARAL, Wagner R.; BAIBICH-FARIA, Tânia Maria. A presença dos estudantes indígenas nas universidades estaduais do Paraná: trajetórias e pertencimentos. Revista Brasileira de Estudos Pedagógicos, v. 93, n. 235, p. 818-835, 2012.

3. AMARAL, Wagner R. Trajetórias dos estudantes indígenas nas universidades estaduais do Paraná: sujeitos e pertencimentos. 2010. Tese (Doutorado em Educação) - Setor de Educação, Universidade Federal do Paraná, Curitiba, 2010.

4. AMES, Valesca D. B. Indígenas no ensino superior: uma análise sobre a formação dos estudantes Kaingang da Universidade Federal do Rio Grande do Sul. 2019. Tese (Doutorado em Sociologia) - Instituto de Filosofia e Ciências Humanas, Universidade Federal do Rio Grande do Sul, Porto Alegre, 2019.

5. BARDIN, Laurence. Análise de conteúdo. São Paulo: Edições 70, 2011.

6. BERGAMASCHI, Maria Aparecida; DOEBBER, Michele B.; BRITO, Patrícia O. Estudantes indígenas na Universidade Federal do Rio Grande do Sul - desafios do acesso e permanência. Revista del Cisen Tramas/Maepova, v. 4, n. 2, p. 167 $184,2016$.

7. BOURDIEU, Pierre. A escola conservadora: as desigualdades frente à escola e à cultura. In: NOGUEIRA, Maria Alice; CATANI, Afrânio (orgs.). Escritos de educação. Petrópolis: Vozes, 2007. p. 39-64.

8. BRASIL. Lei $\mathrm{n}^{\circ}$ 12.711. Dispõe sobre o ingresso nas universidades federais e nas instituições federais de ensino técnico de nível médio e dá outras providências. Diário Oficial da União, Brasília, DF, 30 ago. 2012. Seção 1, p. 1.

9. BRASIL. Constituição da República Federativa do Brasil. Brasília, DF: Senado Federal - Centro Gráfico, 1988.

10. CESAREO, Vincenzo. Sociologia: teorie e problemi. Milão: Vita e Pensiero, 1993.

11. CIPOLLINI, Roberta. Stranieri. Percezione dello straniero e pregiuzidio etnico. Milão: Franco Angeli, 2002.

12. COULON, Alain. O ofício de estudante: a entrada na vida universitária. Educação e pesquisa. São Paulo, v. 43, n. 4, p. 1239-1250, 2017.

13. COULON, Alain. A condição de estudante: a entrada na vida universitária. Salvador: EDUFBA, 2008.

14. DOEBBER, Michele. Indígenas estudantes nas graduações da UFRGS: movimentos de reexistência. 2017. Tese (Doutorado em Educação) - Faculdade de Educação, Universidade Federal do Rio Grande do Sul, Porto Alegre, 2017. 
15. ELIAS, Norbert; SCOTSON, John L. Os estabelecidos e os outsiders: sociologia das relações de poder a partir de uma pequena comunidade. Rio de Janeiro: J. Zahar, 2000.

16. HERINGER, Rosana R. Um balanço de 10 anos de políticas de ação afirmativa no Brasil. Tomo, v. 1, n. 24 p. 13-29, 2014.

17. LIMA, Antônio Carlos de S.; BARROSO, Maria M. A presença indígena na construção de uma educação superior universal, diferenciada e de qualidade. In: LIMA, Antonio Carlos; BARROSO, Maria. (orgs.). Povos indígenas e universidade no Brasil: contextos e perspectivas, 2004-2008, Rio de Janeiro: E-papers, 2013. p. 109-118.

18. MANNHEIM, Karl. Isolamento social. In: CARDOSO, Fernando Henrique; IANNI, Octávio (orgs.). Homem e sociedade: leituras básicas de sociologia geral. São Paulo: Editora Nacional, 1970.

19. MAZZARA, Bruno. Appartenenza e pregiudizio. Psicologia sociale delle relazioni interetniche. Roma: Carocci Editore, 2000.

20. MERTON, Robert. Sociologia: teoria e estrutura. São Paulo: Mestre Jou, 1970.

21. OLIVEN, Arabela C.; BELLO, Luciane. Negros e indígenas ocupam o templo branco: ações afirmativas na UFRGS. Horizontes Antropológicos, v. 23, n. 49, p. 339-374, 2017.

22. OLIVEN, Arabela. Ações afirmativas, relações raciais e política de cotas nas universidades: uma comparação entre os Estados Unidos e o Brasil. Educação, n. 1, p. 29-51, 2007.

23. PALADINO, Mariana. Um mapeamento das ações afirmativas voltadas aos povos indígenas no ensino superior. In: BERGAMASCHI, Maria Aparecida; NABARRO, Edilson; BENITES, Andréa (orgs). Estudantes indígenas no ensino superior: uma abordagem a partir da experiência da UFRGS. Porto Alegre: Editora da UFRGS, 2013.

24. PALADINO, Mariana. Algumas notas para a discussão sobre a situação de acesso e permanência dos povos indígenas na educação superior. Práxis Educativa, v. 7, número especial, p. 175-195, 2012.

25. PAULA, Luis Roberto de. O ensino superior indígena como política pública: elementos para a construção de um modelo metodológico de avaliação e comparação de experiências locais. Revista Brasileira de Estudos Pedagógicos, v. 94, n. 238, p. 795-810, 2013.

26. PIOTTO, Débora Cristina; ALVES, Renata O. O ingresso de estudantes das camadas populares em uma universidade pública: desviando do ocaso quase por acaso. Revista de Educação PUC-Campinas, v. 21, n. 2, p. 139-147, 2016.

27. SIMMEL, Georg. Lo straniero. In: TABBONI, Simonetta (org.). Vicinanza e lontananza. Modelli e figure dello straniero come categoria sociologica. Milão: Franco Angeli, 1986. p. 147-154. 
28. SOARES, Adriana B.; MOURÃO, Luciana.; MOTA, Márcia Maria P. E. da. O estudante universitário brasileiro: características cognitivas, habilidades relacionais e transição para o mercado de trabalho. Curitiba: Appris, 2016.

29. UFRGS. Coordenadoria de acompanhamento do programa de ações afirmativas. Dados do processo seletivo específico para estudantes indígenas, 2008-2017. Porto Alegre, 2017a.

30. UFRGS. Processos seletivos. Processo seletivo específico para ingresso de estudantes indígenas. Edital 08 de dezembro de 2017. Porto Alegre, 2017b. Disponível em: http://www.ufrgs.br/coperse/processos-seletivos/estudantes-indigenas/ pse-estudantesindigenas-2018. Acesso em: 04 abr. 2018.

31. UFRGS. Conselho universitário. Decisão n. 268/2012. Porto Alegre, ago. 2012.

Submetido em: 12 nov. 2019.

Aceito em: 09 abr. 2020. 